\title{
Health Equity Column: Framing the Importance of Health Equity and Antiracism in the NICU
}

Jenné Johns, MPH, Tamorah Lewis MD, PhD, Jamesia Donato MD

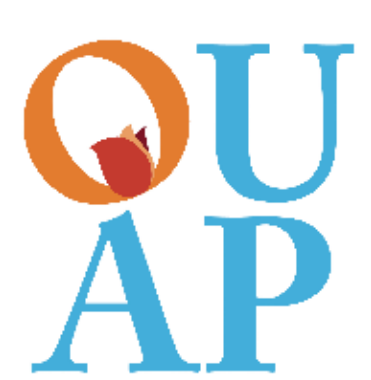

In this month's Health Equity Column, I am honored to share highlights of my interview with two health equity champions in delivering antiracist and equitable neonatal care. Through our interview, you will learn about the health and racial equity-focused strategies and initiatives led by Dr. Lewis at the Children's Mercy Hospital in Kansas City, MO, and from Dr. Donato, a Neonatal-Perinatal Medicine Fellow at Children's Mercy Hospital. As you learn about these timely opportunities to address and reduce healthcare disparities in neonatal care, I encourage you to leverage these resources within your respective institutions and to support the closing of racial and ethnic disparities in perinatal and neonatal health outcomes based on Children's Mercy Hospital health equity framework.

\section{"We also encourage you to join the Once Upon A Preemie Academy on October 28th and November 22nd from 1:00-2:00 pm EST for one hour live CEU trainings."}

We also encourage you to join the Once Upon A Preemie Academy on October $28^{\text {th }}$ and November $22^{\text {nd }}$ from 1:00-2:00 pm EST for one hour live CEU trainings. This year, our theme is: "Going Deeper In Addressing Health and Racial Equity in the NICU." For more information, please visit www.onceuponapreemieacademy. com .

\section{What is your definition of health equity?}

Dr. Lewis: When I think about health equity, the main thing I think about is customized care, a "one size fits all" approach that we generally apply in medicine right now. This systematically disadvantages certain populations. I think one really important aspect of equity is each family comes into the NICU with a different life experience, different medical literacy, and different access to social networks and economic networks. We have to customize our communication, customize our medical care, and really customize the experience of each family in order to have equal health outcomes.

Dr. Donato: My definition of health equity is just finding fairness in all aspects of medicine, treatment, and the patient experience. When it comes to just walking in the door and feeling welcomed to just receiving the standard of care regardless of your race, gender, or socioeconomic background, being treated fairly and the same is essentially how I define health equity.

What are your organizational priorities for addressing health and racial equity in perinatal and neonatal care?

Dr. Lewis: At our big academic children's hospital, there are multiple ways that we are working to improve health equity. The first one is a hospital-wide health equity surveillance system, where there's a team of doctors and other providers that is beginning to systematically collect data to understand disparities in all aspects of the care we provide at the hospital. That can be disparities in what families are accessing telemedicine during the pandemic or if there are certain babies that are more or less likely to get readmitted after discharge.

Those are the kind of disparities that this health equity surveillance system is trying to quantify. Once you can identify and quantify the disparity, you can design interventions to reduce that disparity. Some examples of things we are doing specifically in the NICU include a health equity task force within our Division of neonatology that is run by our division chief, of which I am an active member of. In this task force, we are really doing the hard work of looking at our own data in our own NICU and stratifying outcomes by race to look for racial disparities in NICU outcomes to understand the root causes of those disparities and then to design interventions to mitigate them. One project that is coming out of our health equity task force is understanding how to bring a health equity lens to all of our QI work. Historically in our NICU, our quality improvement projects have not necessarily been designed with a health equity lens. For example, when we look at improvement in whatever outcome of a QI project, we historically have not stratified it by race, so we don't understand everything fully. Are all babies benefiting equally from this intervention? Are there certain racial or primary language sub-cohorts that are not benefitting equally from these QI interventions? For the first time, we're really trying to make a health equity lens required for all of our QI design and also the way we look at the QI data. So that, I think, is a huge step in the right direction.
"Are there certain racial or primary language sub-cohorts that are not benefitting equally from these QI interventions? For the first time, we're really trying to make a health equity lens required for all of our QI design and also the way we look at the QI data. So that, I think, is a huge step in the right direction."

I will say that one of the biggest barriers to health equity and health disparity work is the extremely haphazard and unorganized way that racial data is currently collected in the NICU. We are doing all of our current work based on retrospective data, which is

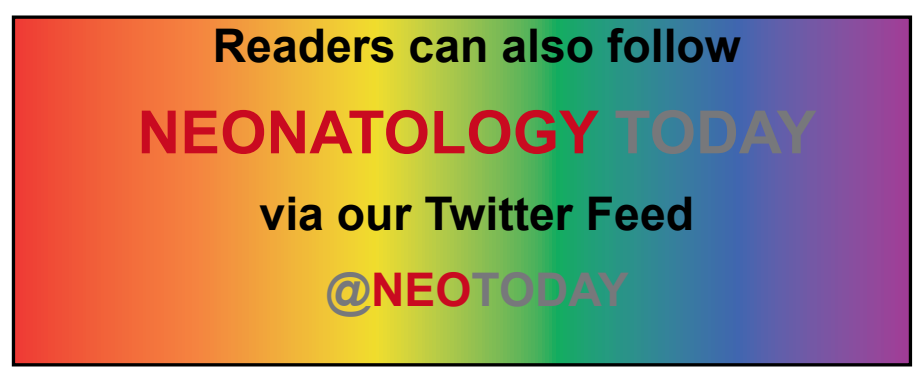


highly variable how maternal and infant race is documented in the medical records. We understand that our data is imperfect, but we are not letting that stop us. There is no granular demographic data in our electronic health record about SES status, about education status, about neighborhood safety, and all of those other really important social determinants of health.

We understand the shortcomings of our current data availability, and now, what we are doing is thinking with the greater hospital health equity surveillance system about if we were going to change things going forward, how would we change our data collection to facilitate improved health equity and QI work? That is really equity-focused. For example, right now, we are launching a project in multiple divisions in the hospital. It is not just the NICU, but we are participating prospectively by going to actually ask families, "What is your family's racial and ethnic background?" We plan to ask this about moms, dads, and babies in a very structured standard way.

"Our hope is that we can show that this data is much more valuable than the way it is currently collected in the EHR now. We cannot even really pinpoint where the current racial data comes from with the help we collected, so I will not even pretend to explain how we do it now."

Our hope is that we can show that this data is much more valuable than the way it is currently collected in the EHR now. We cannot even really pinpoint where the current racial data comes from with the help we collected, so I will not even pretend to explain how we do it now. However, what we do know is that it probably has some inaccuracies. Also, we are not doing justice to the wide range of racial and ethnic backgrounds that are in our NICU because we are trying to pigeonhole this amazingly diverse group of families into two or three categories.

Dr. Donato: As a recent fellowship graduate from neonatology at Children's Mercy, one of the things that I really appreciated, especially with the racial climate that is currently present in this country, is that our division leader was very transparent about his desire to identify racial disparities, health inequities, and even took the time to create a safe and protected space for our entire Division to share personal experiences, concerns, and situations where families may have been treated differently or may not have been serviced best in our NICU.

That was really powerful for me, to see our leadership passionate about it, determined about it, and open to hearing different professional experiences from physicians, nurse practitioners, nurses, and trainees. Also, to be invited to that forum as a trainee was very helpful and provided more transparency in that forum. I remember several sessions where Dr. Lewis touched on health equity. I don't think people's minds immediately went there, but I think the most important part of it is that people were able to candidly share situations where they had actively participated in committing something that may have made someone not feel like they were receiving equitable care. People are able to report experiences where they may have noticed some maltreatment or situations where we could have made patients' or families' experiences better, and people were on board with learning how to bet- ter meet families where they are. I thought that was a really good intervention that may still be ongoing in our Division.

\section{What personal and professional experiences led you to focus on health equity in perinatal and neonatal care?}

Dr. Lewis: I remember being in medical school, and we were taught that health disparities were kind of a foregone conclusion. We were taught that certain populations have worse outcomes than others -- end of sentence. We didn't benefit as medical students from the really rich sociologic practices like the critical race theory and structural competency, all of the things that could have put those disparity data and statistics into a larger context in a way that medical trainees and physicians would feel empowered to address them and eliminate them. As I went through residency and fellowship, I became more knowledgeable about the deeply entrenched disparities in maternal outcomes, perinatal outcomes, and neonatal outcomes. The honest truth is, I just became so disillusioned with the fact that more people in power in academic medicine were not openly talking about this, funding research about this, designing interventions, and studying interventions about this.

I really came to realize that health disparities are one of the many challenges in medicine, and they really have been neglected when it comes to research, interventions, and elimination. I want to be clear that it is not because people are not smart enough or driven enough in medicine. We have tackled the most complex, molecularly diverse cancers. We have taken a whole new viral pandemic and created advanced vaccines in less than a year. There is something unique about health disparities that have made that issue in medicine chronically neglected.

I think the unique aspect is that many of the providers in medicine will never experience the impact of those disparities, and no one in their family and close circle of friends will ever experience the impact of those disparities, so there is less urgency. People are not equipped with the larger sociological knowledge to understand that these disparities are not based on biology or genetics; they are based on the societal experience of being a minority, whatever that minority subgroup may be in the United States.

\section{"People are not equipped with the larger sociological knowledge to understand that these disparities are not based on biology or genetics; they are based on the societal experience of being a minority, whatever that minority subgroup may be in the United States."}

That's a very long-winded answer to say that I am passionate about eliminating health disparities and improving health equity because I know that I'm one of the few voices in academic medicine that is willing to do the hard work of learning this new topic that we were never taught in our medical training. I am willing to do the hard work of educating my colleagues about the topic and willing to do the hard work of spending professional capital social capital, knowing that I will offend people and will alienate myself at times by speaking loudly and proudly about these disparities and our need to eliminate them.

Because I am in the minority in academic medicine, I have this deep sense that if I do not help do this, who will? Historically, 
the answer has been, "We have made very little progress in the elimination of health disparities, not just in perinatal and neonatal care, but all across medicine." More time is not an option for me. Patients are suffering every day. Mothers are dying every day. Preterm infants are dying every day. We need to begin to work on this now actively. I can't sit with that truth and that reality and not act on my feelings. I feel compelled to make a change.

Dr. Donato: Really, what I think led me to neonatology is probably what makes health equity important to me. I was a premature baby being born at twenty-six weeks back in the nineteen-eighties. My mom shared several experiences with me about how she may have felt judged or not treated fairly because we were more of a low, middle-class family. Maybe she could have received counseling on the prenatal end so that she would be able to gain more knowledge that maybe could have prevented a premature outcome.

We have had those discussions. I think that experience as a twenty-six-week-old premature baby in the nineteen-eighties really fueled my passion for really dedicating my life to neonatology. Naturally, being a minority in medicine with the personal experience of prematurity and some of the statistical outcomes that were projected onto my life even before I was out of the womb really remain important to me, and I really strive to not create those same experiences for families. I think a lot of times, lack of health equity or lack of socioeconomic equity is what drives a lot of minority mothers to be a part of this health disparity that currently exists. For this reason, I am very passionate about maternal mortality and very passionate about infant mortality. I think the only way that we can truly address these issues systematically is to start with health equity. That is kind of my personal experience and why I am so passionate about it. I really feel like not only is this a job, but this is really my life's work.

This is truly why I survived prematurity, and it is really my goal to make sure that families coming behind me that look like me really have a better experience and just get better access to care upstream before the prematurity happens, before the NICU experience happens so that we can have better outcomes overall for all patients and specifically minorities.

What is your call to action for the industry as we seek to eliminate health and racial inequities in perinatal and neonatal care?

Dr. Lewis: It is interesting; just last week, I spoke with a group of medical students in Kansas City, and I told them what my call to action is for them. I told them, "You are still early in your medical training. I beg of you to make your passion for learning and understanding structural inequity in this country, structural racism, and the core determinants of health, which are far outside the walls of medicine. Please make that as much of a priority for what you learn to later serve your patients as you do learning about the heart, the lungs, medicines, and surgeries because if you come out of your training and you lack this critical understanding, health disparities will not improve." That is my same call to action for even all practicing providers in neonatology that are done with their training. They need to make space to learn about and think about these very difficult topics because the brutal truth is that if you are not doing that, you are not serving your patients of color to the optimal amount.
Dr. Donato: I think for me, being a research fellowship graduate and knowing how it felt to be a minority even in training, one of my big calls to action is for graduate medical education to also prioritize health disparities and health equity as a part of our training. I think it is important, certainly, as Dr. Lewis mentioned, for it to be ingrained very early. Maybe we need to start talking about it in a pre-medical curriculum in college. We certainly need to prioritize it in medical training.

As you get closer and closer to being an active practicing provider and available provider, these topics need to be prioritized. We glaze over them occasionally. Every now and then, it is implemented in a common curriculum, or maybe we get a lecture here and there. If we are even lucky, we might get a grand round presentation, but that is very rare as trainees. This needs to be prioritized in our education.

Then, my next call to action would be to my colleagues in academia and in private practice. As I embark on a career in private practice, one of my biggest fears is that these minority populations may be more apparent to me because a lot of times, dollars drive private practice. Continuing to prioritize this population is going to be a big deal for me. Calling not only my fellow neonatologists to action to make it a priority but also calling hospital leadership in the private practice world to understand that yes, dollars matter, but patient experiences within your hospital and within the NICU matter.

"NICUs are powerful whether they realize it or not. They are big dollar drivers for these hospitals. Our voices should be heard, and our concerns should be prioritized. I think it is our duty as practicing providers within that very special population to make that heard and to make that a continual priority."

NICUs are powerful whether they realize it or not. They are big dollar drivers for these hospitals. Our voices should be heard, and our concerns should be prioritized. I think it is our duty as practicing providers within that very special population to make that heard and to make that a continual priority.

Disclosure: The authors have no disclosures.

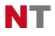

NEONATOLOGY TODAY is interested in publishing manuscripts from Neonatologists, Fellows, NNPs and those involved in caring for neonates on case studies, research results, hospital news, meeting announcements, and other pertinent topics.

Please submit your manuscript to: LomaLindaPublishingCompany@gmail.com 


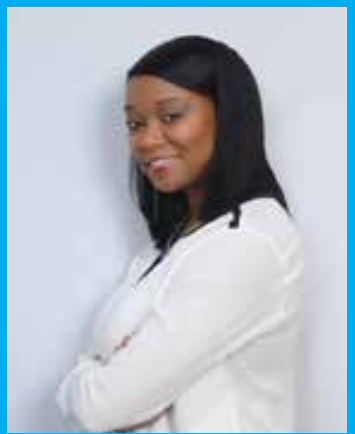

President, Once Upon A Preemie www.onceuponapreemie.com

Founder, Once Upon A Preemie Academy www.onceuponapreemieacademy.com

Jenné Johns, MPH is President of Once Upon A Preemie, Founder of Once Upon A Preemie Academy, mother of a micropreemie, author, speaker, advocate, and national senior health equity leader. Once Upon A Preemie is a non-profit organization with a two-part mission: 1.) to donate Once Upon A Preemie books to NICU families in under resourced communities, and 2.) lead virtual health and racial ethnic training programs and solutions to the neonatal and perinatal community through the Once Upon A Preemie Academy. Jenné provides speaking, strategic planning and consultation services for fortune 500 companies focused on preemie parent needs from a cultural lens and reading as a tool for growth, development, and bonding. Jenné is also a national senior health equity thought leader and has led solutionsoriented health equity and quality improvement portfolios for the nations' largest health insurance and managed care companies.

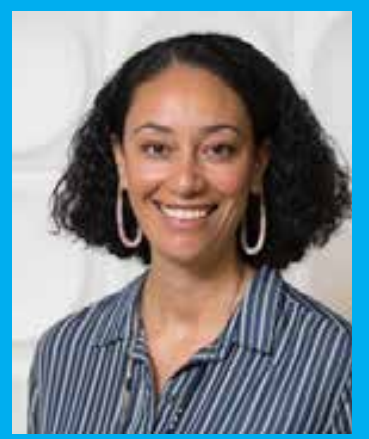

Title: Physician and Researcher and Associate Professor

Organization: Physician and Researcher, Children's Mercy Hospital in Kansas City, MO and Associate Professor, The University of Missouri, Kansas City School of Medicine

Bio: Tamorah Lewis MD, PhD is a physician and researcher at Children's Mercy Hospital in Kansas City, MO. She is dual trained in neonatal/perinatal medicine and clinical pharmacology. Her research program focuses on developmental pharmacology and pharmacogenetics in the neonatal population. As an Associate Professor in the Department of Pediatrics at The University of Missouri, Kansas City School of Medicine, she practices clinical neonatology. She works collaboratively to design, implement, and manage her clinical and translational research program in Neonatal Precision Therapeutics. The overarching goal of her research program is to bring individualized medicine to the NICU population using modern pharmacology tools. Her research career will focus on elucidating the pharmacokinetics, pharmacodynamics, and pharmacogenetics of both old and new drugs used to treat neonatal disease, emphasizing optimizing and individualizing drug therapy in neonates.

Dr. Lewis serves as the Director of Clinical Research Logistics for her Division. She has established the Maternal Neonatal Pharmacogenetic Repository at Children's Mercy Hospital and has multiple prospective pharmacogenetic cohort studies enrolling and depositing diverse bio-samples to this repository. In addition, she has established research collaborations at UCSF (steroid pharmacogenetics), Vanderbilt (ductus arteriosus pharmacogenetics), and the University of Buffalo (NSAID PK). She is actively engaged as site PI in multi-site studies assessing neonatal drug safety and efficacy.

Dr. Lewis is actively engaged in research societies. She sits on the Board of Directors for the American Society of Clinical Pharmacology and Therapeutics and is on the Executive Committee of the American Academy of Pediatrics (AAP) Section on Clinical Pharmacology and Therapeutics. Dr. Lewis is also a member of the International Neonatal Consortium, a multi-stakeholder collaboration run by the Critical Path Institute to advance neonatal therapeutics. 


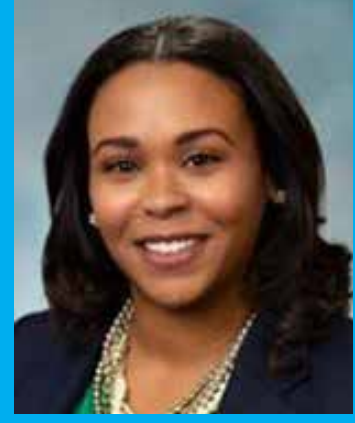

Title: Neonatologist

Organization: Sunflower Neonatology

Bio: Dr. Donato is from Atlanta, GA, and received her medical degree from Meharry Medical College in Nashville, TN. She moved to Kansas City and completed her residency training in Internal Medicine and Pediatrics at the University of Missouri-Kansas City/Children's Mercy Hospital and completed her Neonatal-Perinatal Medicine fellowship training at Children's Mercy Hospital. She is passionate about improving the care of preterm and term neonates through the systematic study of health disparities and health inequities amongst minoritized populations. As a previous 26week gestation neonate, this field is more than just a job; it is truly her purpose and life's work to accomplish. She is married and loves spending time with her husband and two dogs. She volunteers with Big Brothers Big Sisters of Kansas City and enjoys running, softball, reading, yoga/pilates, and baking.

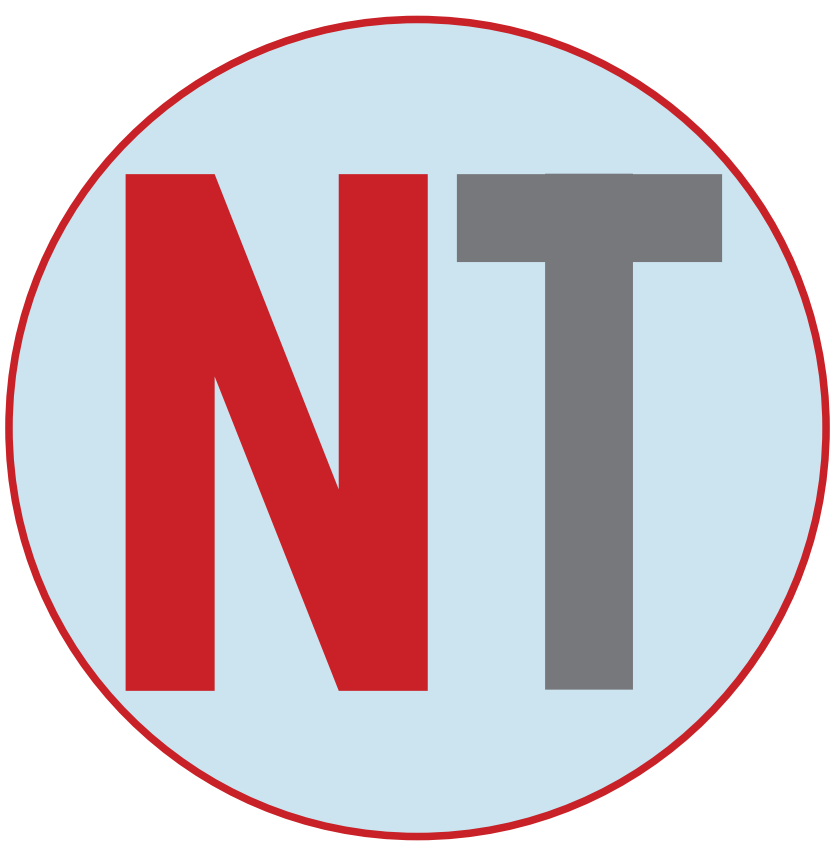

NEONATOLOGY TODAY is interested in publishing manuscripts from Neonatologists, Fellows, NNPs and those involved in caring for neonates on case studies, research results, hospital news, meeting announcements, and other pertinent topics.

Please submit your manuscript to: LomaLindaPublishingCompany@gmail.com 